\section{Using the real-life vision test to assess the functional vision of age-related cataract patients}

W Ni, X Li, M Ao, H Zhang, Z Hou, S Si

and W Wang
Department of

Ophthalmology, Peking

University Third Hospital,

Beijing, China

Correspondence:

W Wang, Department of Ophthalmology, Peking University Third Hospital, No. 49 North Garden Road, Haidian District, Beijing, 100191, China

Tel: +8610 82268106; Fax: +861082266649. E-mail: puh3_ww@bjmu. edu.cn

Received: 5 September 2011

Accepted in revised form:

6 July 2012

Published online: 10 August 2012

\begin{abstract}
Purpose (1) To describe and validate a newly developed, timed performance-based measures of functional vision-the real-life vision test (RLVT). (2) To determine how RLVT relates to clinical measures and selfreport assessment of visual function and the complex interactions among visual impairment, psychosocial status, and demographic factors.

Methods A total of 64 patients with age-related cataract and 45 age-matched controls were evaluated by four types of measurements: (1) demographic, medical, cognitive, and depressive evaluation and the reaction time (RT) testing; (2) clinical measures (visual acuity, contrast sensitivity, stereopsis, and the color perception); (3) the 25-item National Eye Institute's Visual Functioning Questionnaire; and (4) the RLVT. Spearman's coefficients, partial correlation, and multiple regression analysis were conducted to determine the relationship among RLVT, clinical measures, and selfreport assessment of visual function while controlling for confounders. Results Control subjects performed RLVT significantly better than the cataract patients. RLVT correlated well with both clinical and self-report assessments of visual function. All subscales of RLVT remained highly associated with most of the clinical measures, even after adjusting for age, years of education, depression, cognitive status, and the RT. Distance, intermediate and near visual acuity, and binocular contrast sensitivity were significant predictors of the RLVT performances.

Conclusions Given the strong relationship among RLVT, clinical measures, and the self-report assessments, our results highlight the potential usefulness of RLVT for
\end{abstract}

assessing the functional vision of cataract patients. RLVT may provide information not obtainable from clinical measures or surveys and therefore it is essential to be incorporated into future ophthalmological practice.

Eye (2012) 26, 1402-1411; doi:10.1038/eye.2012.168; published online 10 August 2012

Keywords: functional vision; age-related cataract; performance-based measures; real-life vision test

\section{Introduction}

Visual ability serves as an essential part in daily life. Many visually impaired people have varied difficulties in daily activities. Such inability usually causes numerous deleterious outcomes, such as physical disability, ${ }^{1}$ psychosocial distress, ${ }^{2,3}$ and low quality of life. ${ }^{4-9}$ Therefore, it is important to understand how visual impairments influence our daily life.

Currently, the most-accepted assessments of visual function are the clinical tests, such as visual acuity and visual field. However, they may be inadequate in explaining impairments of everyday performance. Vision-related questionnaires and surveys have grown by a big margin in recent years. ${ }^{7,9-16}$ They provided key information about the impact of visual damage from the patients' perspective. However, the results of the questionnaires are usually subjective, overreported or underreported owing to diversified factors other than visual diseases, such as personal biases, desire to please, and desire to mislead. ${ }^{2,10,17}$ Based on the inherent limitations of clinical tests and self-report questionnaires, more recently there has been an upcoming interest in developing a complementary method for evaluation and 
outcome measures of visual function-the performancebased measures (PBMs) of visual function. 4,10,13,18-27

Vision-specific PBMs take on actual performance of vision-related tasks. It involves presenting patients with commonly encountered tasks of daily life in a standardized format and getting a grade in accordance to their visual ability to complete the tests. In such way, it could measure the visual disability directly by assessing what a person 'can see' in real life. It can also effectively combine the objective nature of traditional assessment with the patient's actual ability in daily life.

Pioneering work in the development of PBMs has demonstrated that this kind of assessment can be a reliable and valid method in assessing visual ability. ${ }^{13,18,20,23-26}$ However, little research has been done on Chinese population so far. Because PBMs are designed to understand how patients react in real-life activities, the 'tasks' that we selected should cover the most usual activities in daily life. Of course, considerable difference may exist in various cultures. In this way, it might be more valid if the tasks selected are designated to culturally specific activities.

In our study, a new type of vision-specific PBM was developed-the real-life vision test (RLVT). The specific aims were: (1) to describe and validate the RLVT; (2) to determine how RLVT relates to both clinical measures and self-report assessment of visual function and the complex interactions among visual impairment, psychosocial status, as well as demographic factors, and how they act together to affect one's visual ability to act in everyday life. In this study, we went through the standard clinical tests, self-reported quality of life survey, and the RLVT in age-related cataract and control subjects. Patient-related and disease-related factors, which may potentially influence their activities, were also examined.

\section{Materials and methods}

The research followed the tenets of the Declaration of Helsinki, informed consent was obtained from all subjects after the nature and possible consequences of the procedure had been fully explained. The study protocol was approved by an institutional review board. All the participants in the study were recruited after they were given detailed explanation of the research.

\section{Cataract subjects}

Sixty-four subjects with bilateral uncomplicated agerelated cataract were selected, conforming to rigid inclusion criteria: between 60 and 82 years of age, bilateral visual acuity range from 0.2 to 1.0 ( $\log \mathrm{MAR})$, no other ocular disease other than refractive error, no history of ocular surgery, no neurological, or musculoskeletal deficits. The distance of spherical refractive error of both eyes ranged from +3.00 to $-3.00 \mathrm{D}$ sphere, and the maximum power of the cylinder was 3.00D. Subject with low intellectual level or cognitive/depressive problems (defined as a score of $\leq 25$ on the Mini Mental State Examination (MMSE), ${ }^{28}$ or with a score of $\geq 41$ on the self-rating depression scale (SDS), ${ }^{29}$ was also excluded.

\section{Control subjects}

A total of 45 age-matched subjects with no ocular disease except for refractive error were used as controls. The same inclusion criteria of the cataract group were used, with the additional criteria that bilateral visual acuity of $0.1 \log$ MAR or better and an interocular acuity difference of $<0.1 \log$ MAR. Those with a stereopsis worse than $60 \mathrm{~s}$ of arc were excluded. Those with minimal nuclear sclerosis $(<\mathrm{NI})^{30}$ were eligible for inclusion because of the high prevalence of lens opacity among the people older than 70 years old.

\section{Clinical settings}

All participants were tested under binocular viewing conditions with recent habitual optical correction. Each participant was given a standard examination by ophthalmoscopy and slit-lamp biomicroscopy. A full range of clinical measures (near, intermediate and distance visual acuity, contrast sensitivity, depth perception, and color vision test) were included. Distance visual acuities were measured using a front lit Bailey-Lovie letter $\log$ MAR chart (Precision Vision, La Salle, IL, USA) at a test distance of $4 \mathrm{~m}$ and scored per correct letter (0.02 logMAR per letter). ${ }^{31}$ Near and intermediate visual acuities were measured with Colenbrander mixed contrast card (Precision Vision) ${ }^{32}$ set at the distance of 40 and $100 \mathrm{~cm}$. Depth perception was measured using the Stereo Fly Test (Precision Vision) and the results were converted into a log scale. Contrast sensitivity was measured with the OPTEC 6500P (2002 Vision Sciences Research Corp., San Ramon, CA, USA) under day and night conditions (luminance levels: 85 and $3.0 \mathrm{~cd} / \mathrm{m}^{2}$ with and without glare, respectively; spatial frequencies: 1.5, 3, 6, 12 and 18 cycles per degree). It was based on the Functional Acuity Contrast Test. ${ }^{33}$ All results were converted into a log scale. Color perception test was performed according to the manufacturer's instruction using the Farnsworthmun-sell 100-hue (FM 100-hue) test. ${ }^{34}$ The total error scores were calculated using the FM 100-hue scoring software (version 3.0, Munsell Color Services Laboratory, New Windsor, NY, USA) with the standard method. 


\section{Demographic data}

Age, gender, years of education, and the medical comorbidities were collected using a standard form. Cognitive status was assessed using the MMSE. ${ }^{28}$ The presence of depressive symptoms were assessed with the SDS. ${ }^{29}$ The reaction time (RT) was measured with a computer-based program (http://www.bbc.co.uk/ science/humanbody/sleep/sheep/reaction_version5.swf). During the test, the subjects were asked to click the mouse as soon as possible when they saw a sheep appearing on the screen. The tests were repeated five times and the average time was recorded as the final RT result.

\section{Self-assessed measures}

Each subject completed the 25-item National Eye Institute Visual Functioning Questionnaire (NEI-VFQ-25).2,11 The total score was calculated according to the scoring algorithm.

\section{The RLVT}

As our final goal was to identify tasks that could have potential use as evaluation measures in the ophthalmological practice, the test items need to be thoughtfully identified. The first step in the development was to directly ask the patients what vision-related troubles they had in daily lives. A special questionnaire was designed on this purpose, including a broad range of vision-requiring tasks representing many domains of daily life for most people regardless of gender, age, educational background, or socioeconomic status. In total, 1062 cataract patients were involved. The result shows that the top six difficulty items were: (1) Recognizing faces; (2) Reading newspapers/books/ magazines; (3) Doing near activities (needlework/ handicrafts); (4) Billboard/street signs recognition; (5) Inserting a key/plug/ pouring water; and (6) Shopping for food/fruit/vegetables. All the RLVT items were selected based on this result in order to develop an instrument that will evaluate the daily tasks of greatest significance to most cataract patients.

Meanwhile, many vision-related questionnaires $7,9,11-16,18,35$ and vision-related PBMs ${ }^{4,10,13,18-27}$ were reviewed.

We chose the tasks that represent the real-life situations as much as possible. Thus, actual everyday life materials (update newspapers, fruits/vegetable models, and real buttons) were used in our study. We tested the lighting conditions by the TES 1335 Light Meter (TES, Taipei, Taiwan) in several real-life places in Beijing (supermarket, shopping mall, bus station, on the street, and at home). The ambient lighting for each task was standardized according to these results. Based on the previous data, ${ }^{19}$ the time duration to complete the tasks was recorded as the primary dependent variable in our analysis. During our pilot research, we found that patients with reading problems (such as a stammering tongue) would use extremely longer time to finish the reading task even when they can see the words clearly. Therefore, a words-picking task was designed, which mainly focus on visual ability and may be less influenced by other sensory skills. Within this broad framework, RLVT was developed (Table 1).

We certify that all applicable institutional and governmental regulations concerning the ethical use of human volunteers were followed.

\section{Statistical analysis}

The Statistical Package for the Social Sciences version 18.0 (SPSS Inc., IBM, New York, NY, USA) was used to perform the statistical analysis. All the tests of statistical significance were two-sided, and $P$-value $<0.05$ were considered statistically significant. Before the analysis, all variables were plotted and reviewed for outliers that might represent data entry errors. The distribution and relationships of all the variables were analyzed. Frequency distributions were used for categorical variables. The differences of all the variables between the cataract group and the controls were evaluated by the independent $t$-test (when the variables were normally distributed) or by the Mann-Whitney $U$-test (when the variables were not normally distributed). Analysis of variance (when the variables were normally distributed) and the Kruskal-Wallis test (when the variables were not normally distributed) were conducted to identify the differences in groups with different types of cataract and categorical variables. Scatter plots were constructed between clinical measures, NEI-25 total scores and RLVT in order to detect the linear relationships. Bivariate relationships were evaluated using the Spearman's nonparametric correlation coefficient. The partial correlation analysis was used to detect the relationships after adjusting for age, years of education, the MMSE scores, SDS scores, and RT. Multiple linear regression analyses using stepwise selection $(P<0.05$ as the selection criterion) were used to determine which clinical measures were significant predictors of RLVT. To keep with accepted statistical practice, six models of clinical measures that share the strongest correlation with each RLVT subscale were contained in the final regression analyses. Before constructing the regression equations, a correlation matrix of the independent variables was used to identify that binocular visual acuity and better eye visual acuity shared a correlation magnitude of 0.89 . Consequently, in 
Table 1 The real-life vision test (RLVT) description

\begin{tabular}{ll}
\hline RLVT (lighting condition) & Description \\
$\begin{array}{l}\text { Task 1. Reading and } \\
\text { Chinese character picking } \\
\text { (265-275lux) }\end{array}$ & $\begin{array}{l}\text { Under the lighting of two different illumination intensity (265-275lux and 35-40 lux), each subject } \\
\text { is required to pick out six specified Chinese characters from two different newspaper articles } \\
\text { (printed in black with gray background, in regular Chinese script (The six commonly used characters }\end{array}$ \\
$\begin{array}{l}\text { Thinese character picking } \\
\text { are chosen because they involve all of the six Chinese character-making methods)). The six characters } \\
\text { in reduced illumination } \\
\text { (35-40lux) }\end{array}$ & $\begin{array}{l}\text { are given in the title of the test paper and each character appears only once in the article. The size } \\
\text { of each character is } 4 \times 4 \mathrm{~mm}^{2} \text {. The subject may read in silence, but must read through the articles } \\
\text { character by character from the very beginning to the end, and mark each character that is picked out. } \\
\text { After the test, the doctor will ask the patient about the general idea of the articles, to make sure that } \\
\text { due attention is paid to the reading. }\end{array}$
\end{tabular}

Task 3. Fruit and vegetable picking (320-330lux)

Task 4. Button matching (145-155lux)

Task 5. Street signs/ billboard recognition (1300-1350 lux)

Task 6. Face recognition (1300-1350 lux)
Fruit and vegetable models, which are identical to real ones in size, shape and color, are placed on a table $1 \mathrm{~m}$ away from the subjects. There is a price tag stuck to each model, the size of the words on the tags is $1 \times 1 \mathrm{~cm}^{2}$. Different fruits have different prices, and even the same kind of fruit has 2-3 different prices. Subjects are given a list and are asked to pick out the right fruit/vegetable with the right price (a 2.0 Yuan peach, a 3.0 Yuan red apple, a 6.0 Yuan green apple, an 4.5 Yuan orange, a 3 Yuan yellow pepper, a 8 Yuan mango, a 5.5 Yuan yellow pear, a 3.5 Yuan tomato) in turn and put them into a hand bag. Subjects are not allowed to touch the models before they make the decision, so as to reduce the influence of other factors.

Subjects are given 12 dark-colored buttons ( 6 pairs, similar in color and size, with an average diameter of $1 \mathrm{~cm}$ ), which are randomly put on a puce table 0.5 metre away. The subjects are not permitted to touch the buttons before start. First, they are asked to match the 12 buttons into 6 pairs, and then thread a transparent silk string in turn through them one by one. Subjects should get a clear sight of the buttonhole before they thread the string, instead of threading it by hand-touch feeling.

This test uses the same method of face recognition mentioned below: to play slides of billboards/road signs/bus stop boards (eight colored pictures taken from public places in Beijing), the size of which vary from 10 to $20 \mathrm{~cm}$ (in height), each $1 \mathrm{~cm}$ bigger than previous one. Subjects are seated $4 \mathrm{~m}$ away from the screen, and are asked to tell the content of the billboards/street signs/bus stop boards. They can play the slides and turn the photo into a bigger size by clicking the mouse. The timing of the test is the same as that of the face recognition.

The task is measured by presenting the standardized faces of varying sizes to simulate normal-sized faces at different viewing distances. Test stimuli black and white pictures, with $100 \times 100$ pixels, were selected from the Yale Face Database. All faces were cropped at the inner hairline to prevent recognition on the basis of distinctive hairline, color, or style. The pictures are played in slides and projected onto a screen $4 \mathrm{~m}$ away from the patients. Faces on the screen could be enlarged from 10 to $25 \mathrm{~cm}$ (16 gradation for each picture, the length of faces in each picture is $1 \mathrm{~cm}$ longer than the previous one). The subjects were asked one detailed question about each picture. (Picture 1: Male or female?; Picture 2: Chinese or foreigner?; Picture 3: Young or old?; Picture 4-7: Describe the facial expression: happy, angry, scared, sad, or surprised; Picture 8: Wearing a pair of glasses or not?) Before the test, we would give an elaborate explanation of the test by giving examples. After the subjects fully understood the questions, the test would begin (the timer is started). They are allowed to play the slides (gradually enlarging the pictures) by clicking the mouse by themselves if they could not see the picture clearly; if the subjects do not click the mouse after $3 \mathrm{~s}$, the slides would play the next picture automatically until they get the correct answer (the timer is stopped). Then the slides would go to the next picture until the end. No repetition of slides is allowed, participants are asked not to guess if they were unsure, and no feedback is given. the context where both of them were significantly correlated with the RLVT, the clinical variable with a larger correlation magnitude was chosen for inclusion.

\section{Results}

A total of 109 subjects completed the study. Table 2 provides a summary of the subject characteristics, clinical ophthalmic characteristics, RLVT results, and NEI-VFQ-25 total scores with respecting to all independent variables. Kruskal-Wallis test revealed that there were no differences in RLVT or NEI-VFQ-25 scores due to gender or types of cataract. Age was found to be significantly related to the street signs recognition in both groups. The number of educational years, RT, and MMSE scores were significantly correlated with most of the 
Table 2 Participant characteristics, clinical measures of visual function, RLVT, and NEI-VFQ-25 total scores

\begin{tabular}{|c|c|c|c|c|c|}
\hline \multirow[t]{2}{*}{ Variables } & \multicolumn{2}{|c|}{ Cataract group $\mathrm{n}=64$} & \multicolumn{2}{|c|}{ Normal group $\mathrm{n}=45$} & \multirow[t]{2}{*}{$\mathrm{P}$} \\
\hline & Mean (SD) I & Median & Mean (SD) & Median & \\
\hline Age & $69.30(5.66)$ & 68.50 & $67.42(5.37)$ & 67.00 & 0.08 \\
\hline $\begin{array}{l}\text { Educational } \\
\text { years }\end{array}$ & $11.13(3.68)$ & 12.00 & $11.78(3.58)$ & 12.00 & 0.33 \\
\hline MMSE & $28.67(1.57)$ & 30.00 & $28.84(1.58)$ & 30.00 & 0.59 \\
\hline SDS & $35.34(3.40)$ & 36.00 & $28.49(3.06)$ & 29.00 & $P<0.001$ \\
\hline RT & $0.40(0.04)$ & 0.39 & $0.40(0.05)$ & 0.40 & 0.84 \\
\hline NEI-VFQ-25 & $72.71(9.99)$ & 72.08 & $97.02(2.17)$ & 97.17 & $P<0.001$ \\
\hline \multicolumn{6}{|c|}{ Distance visual acuity (logMAR) } \\
\hline Binocular & $0.46(0.16)$ & 0.43 & $0.00(0.10)$ & 0.02 & $P<0.001$ \\
\hline Better eye & $0.49(0.16)$ & 0.50 & $0.03(0.10)$ & 0.06 & $P<0.001$ \\
\hline Worse eye & $0.66(0.21)$ & 0.62 & $0.11(0.09)$ & 0.12 & $P<0.001$ \\
\hline \multicolumn{6}{|c|}{ Near visual acuity (logMAR) } \\
\hline Binocular & $0.50(0.14)$ & 0.50 & $0.13(0.08)$ & 0.14 & $P<0.001$ \\
\hline Better eye & $0.54(0.14)$ & 0.53 & $0.17(0.07)$ & 0.18 & $P<0.001$ \\
\hline Worse eye & $0.68(0.20)$ & 0.66 & $0.25(0.08)$ & 0.26 & $P<0.001$ \\
\hline \multicolumn{6}{|c|}{ Intermediate visual acuity (logMAR) } \\
\hline Binocular & $0.51(0.13)$ & 0.52 & $0.05(0.09)$ & 0.06 & $P<0.001$ \\
\hline Better eye & 051 (0 13) & 0.57 & 8) & 0.10 & $P<0.001$ \\
\hline Worse eye & $0.68(0.14)$ & 0.68 & $0.19(0.10)$ & 0.20 & $P<0.001$ \\
\hline $\begin{array}{l}\text { Stereopsis } \\
(\log )\end{array}$ & $2.27(0.42)$ & 2.15 & $1.72(0.07)$ & 1.78 & $P<0.001$ \\
\hline Color vision & 139.38 & 138.00 & $52.49(10.88)$ & 52.00 & $P<0.001$ \\
\hline \multicolumn{5}{|c|}{ CS (log units) $\left(85 \mathrm{~cd} / \mathrm{m}^{2}\right)$} & $P<0.001$ \\
\hline $1.5 \mathrm{cpd}$ & $1.46(0.24)$ & 1.40 & $1.78(0.11)$ & 1.85 & $P<0.001$ \\
\hline $3 \mathrm{cpd}$ & $1.45(0.25)$ & 1.46 & $1.85(0.11)$ & 1.90 & $P<0.001$ \\
\hline $6 \mathrm{cpd}$ & $1.35(0.35)$ & 1.36 & $1.76(0.11)$ & 1.81 & $P<0.001$ \\
\hline $12 \mathrm{cpd}$ & 0.83 & 1.04 & $1.47(0.12)$ & 1.48 & $P<0.001$ \\
\hline $18 \mathrm{cpd}$ & $0.38(0.38)$ & 0.60 & $1.10(0.14)$ & 1.08 & $P<0.001$ \\
\hline \multicolumn{6}{|c|}{ CS (log units) $\left(3 \mathrm{~cd} / \mathrm{m}^{2}\right)$} \\
\hline $1.5 \mathrm{cpd}$ & $1.37(0.26)$ & 1.26 & $1.69(0.15)$ & 1.70 & $P<0.001$ \\
\hline & $1.21(0.38)$ & 1.18 & & 1.76 & $P<0.001$ \\
\hline & $0.99(0.52)$ & 1.08 & $1.62(0$. & 1.65 & $P<0.001$ \\
\hline & 0.3 & 0.00 & & 1.34 & $P<0.001$ \\
\hline $18 \mathrm{cpd}$ & $0.12(0.24)$ & 0.00 & $0.90(0.18)$ & 0.90 & $P<0.001$ \\
\hline \multicolumn{6}{|c|}{ CS with glare (log units) $\left(3 \mathrm{~cd} / \mathrm{m}^{2}\right)$} \\
\hline $1.5 \mathrm{cpd}$ & $1.03(0.40)$ & 0.95 & $1.47(0.19)$ & 1.40 & $P<0.0$ \\
\hline $3 \mathrm{cpd}$ & $0.80(0.59)$ & 1.00 & $1.50(0.20)$ & 1.46 & $P<0.001$ \\
\hline & $0.53(0.60)$ & 0.00 & $1.38(0.18)$ & 1.36 & $P<0.001$ \\
\hline$d$ & $0.06(0.22)$ & 0.00 & $1.06(0.16)$ & 1.04 & $P<0.001$ \\
\hline $18 \mathrm{cpd}$ & $0.00(0.00)$ & 0.00 & $0.68(0.60)$ & 0.18 & $P<0.001$ \\
\hline \multicolumn{6}{|l|}{ RLVT } \\
\hline Task 1 . & $88.47(23.74)$ & 90.53 & $50.52(6.96)$ & 52.43 & $P<0.001$ \\
\hline Task 2. & $111.78(22.04)$ & 117.62 & $62.56(8.25)$ & & $P<0.001$ \\
\hline Task 3. & $66.41(13.42)$ & 66.14 & $44.69(3.54)$ & 45.19 & $P<0.001$ \\
\hline Task 4. & 89.09 (15.42) & 88.78 & $57.24(3.65)$ & 57.67 & $P<0.001$ \\
\hline Task 5. & $41.34(6.82)$ & 41.69 & $26.48(3.91)$ & 26.23 & $P<0.001$ \\
\hline Task 6. & 58.55 (16.20) & 58.15 & $31.74(4.27)$ & 30.90 & $P<0.001$ \\
\hline
\end{tabular}

Abbreviations: cpd, cycles per degree; CS, contrast sensitivity; logMAR logarithm of the minimum angle of resolution; MMSE, Mini Mental State Examination; NEI-VFQ-25, 25-item National Eye Institute Visual Functioning Questionnaire; RLVT, real-life vision test; RT, reaction time; SDS, self-rating depression scale; Task 1 , reading and Chinese characterpicking task; Task 2, reading and Chinese character-picking task in the reduced illumination; Task 3, Fruit and vegetable picking; Task 4 buttons matching; Task 5, street sign/billboard recognition; Task 6, face recognition.

RLVT performance (Table 3). There was no statistical correlation of any of the task scores with SDS scores, however, the NEI-VFQ total scores were significantly correlated with the SDS scores $(r=-0.476, P<0.01)$.
Comparisons between the cataract group and the control group

No statistically significant differences were found between the two groups in terms of age, gender distribution, years of education, RT, and MMSE scores $(P>0.05)$. However, there was a significant difference on all the clinical measures, NEI-VFQ total scores, and the SDS scores $(P<0.01)$. As detailed in Table 2, control subjects performed significantly better than the cataract patients in the RLVT $(P<0.01)$.

\section{Relationship between RLVT and the clinical measures}

As displayed in Table 3, the time to perform RLVT in the cataract group is significantly correlated with most of the clinical measures. Most of the clinical test had a higher correlation with the RLVT than with the total NEI-VFQ-25 score. Partial correlation analysis demonstrated that all the RLVT subscales remained highly associated with most of the clinical measures, after controlling for age, years of education, MSSE scores, SDS scores, and the RT (Table 4). The strongest relationships among each of the RLVT with the clinical measures existed between:

(1) Reading and binocular near visual acuity $(r=0.72$, $P<0.001)$;

(2) Reading in reduced illumination and binocular near visual acuity $(r=0.64, P<0.001)$;

(3) Fruit and vegetable picking and the contrast sensitivity (luminance levels: $85 \mathrm{~cd} / \mathrm{m}^{2}$; spatial frequencies: 1.5 cpd $)(r=-0.69, P<0.001)$;

(4) Buttons matching and binocular near visual acuity $(r=0.74, P<0.001)$;

(5) Street signs recognition and the better eye distance visual acuity $(r=0.57, P<0.001)$;

(6) Facial recognition and better eye intermediate visual acuity $(r=0.62, P<0.001)$.

Multiple regression analysis demonstrated that the significant clinical predictors of the RLVT subscales include distance, intermediate and near visual acuity, and contrast sensitivity (luminance levels: $85 \mathrm{~cd} / \mathrm{m}^{2}$; spatial frequencies: 1.5 and $3 \mathrm{cpd}$ ).

\section{Relationships between RLVT and NEI-VFQ-25}

Four of the RLVT subscales were statistically correlated with the NEI-VFQ total scores (Table 3). However, after confounding for the age, years of education, MMSE scores, SDS scores, and the RT, none of these statistical associations existed (Table 4). 
Table 3 Correlative analysis-RLVT, clinical measures, and the NEL-VFQ-25 (Spearman's)

\begin{tabular}{|c|c|c|c|c|c|c|c|}
\hline The clinical measures of visual function & Task 1 & Task 2 & Task 3 & Task 4 & Task 5 & Task 6 & NEI-VFQ-25 \\
\hline \multicolumn{8}{|l|}{$V A(\log M A R)$} \\
\hline \multicolumn{8}{|l|}{ Distance } \\
\hline Binocular & $0.49^{* *}$ & $0.55^{* *}$ & $0.68^{* *}$ & $0.66^{* *}$ & $0.60^{* *}$ & $0.65^{* *}$ & $-0.40^{* *}$ \\
\hline Better eye & $0.50^{* *}$ & $0.53^{* *}$ & $0.71^{* *}$ & $0.67^{* *}$ & $0.63^{* *}$ & $0.64^{* *}$ & $-0.37^{*}$ \\
\hline Worse eye & 0.21 & $0.31^{*}$ & $0.25^{*}$ & $0.28^{*}$ & $0.33^{*}$ & $0.33^{*}$ & $-0.51^{* *}$ \\
\hline \multicolumn{8}{|l|}{ Near } \\
\hline Binocular & $0.74^{* *}$ & $0.68^{* *}$ & $0.68^{* *}$ & $0.78^{* *}$ & $0.60^{* *}$ & $0.59^{* *}$ & $-0.32^{*}$ \\
\hline Better eye & $0.70^{* *}$ & $0.65^{* *}$ & $0.72^{* *}$ & $0.78^{* *}$ & $0.60^{* *}$ & $0.61^{* *}$ & $-0.32^{*}$ \\
\hline Worse eye & $0.26^{*}$ & $0.31^{*}$ & $0.27^{*}$ & $0.39 *$ & 0.23 & $0.29^{*}$ & $-0.52^{* *}$ \\
\hline \multicolumn{8}{|l|}{ Intermediate } \\
\hline Binocular & $0.62^{* *}$ & $0.65^{* *}$ & $0.75^{* *}$ & $0.66^{* *}$ & $0.60^{* *}$ & $0.68^{* *}$ & $-0.28^{*}$ \\
\hline Better eye & $0.56^{* *}$ & $0.63^{* *}$ & $0.69^{* *}$ & $0.61^{* *}$ & $0.50^{* *}$ & $0.71^{* *}$ & $-0.29^{*}$ \\
\hline Worse eye & $0.31^{*}$ & $0.35^{*}$ & $0.45^{* *}$ & $0.42^{* *}$ & $0.32^{*}$ & $0.45^{* *}$ & $-0.43^{* *}$ \\
\hline Stereopsis & $0.31^{*}$ & $0.33^{*}$ & $0.26^{*}$ & $0.41^{* *}$ & $0.25^{*}$ & $0.29^{*}$ & $-0.50^{* *}$ \\
\hline Color vision & $0.43^{* *}$ & $0.27^{*}$ & $0.41^{* *}$ & $0.36^{*}$ & 0.20 & $0.34^{*}$ & -0.03 \\
\hline \multicolumn{8}{|l|}{ CS (log units) } \\
\hline \multicolumn{8}{|l|}{$85 \mathrm{~cd} / \mathrm{m}^{2}$} \\
\hline $1.5 \mathrm{cpd}$ & $-0.60^{* *}$ & $-0.61^{* *}$ & $-0.76^{* *}$ & $-0.65^{* *}$ & $-0.50^{* *}$ & $-0.60^{* *}$ & 0.23 \\
\hline $3.0 \mathrm{cpd}$ & $-0.55^{* *}$ & $-0.56^{* *}$ & $-0.60^{* *}$ & $-0.67^{* *}$ & $-0.51^{* *}$ & $-0.49^{* *}$ & $0.34^{*}$ \\
\hline $6.0 \mathrm{cpd}$ & $-0.49^{* *}$ & $-0.47^{* *}$ & $-0.47^{* *}$ & $-0.63^{* *}$ & $-0.38^{*}$ & $-0.43^{* *}$ & $0.48^{* *}$ \\
\hline $12.0 \mathrm{cpd}$ & $-0.31^{*}$ & $-0.25^{*}$ & -0.24 & $-0.35^{*}$ & -0.17 & $-0.30^{*}$ & $0.38^{*}$ \\
\hline $18.0 \mathrm{cpd}$ & $-0.26^{*}$ & -0.19 & $-0.27^{*}$ & $-0.25^{*}$ & -0.12 & -0.18 & $0.33^{*}$ \\
\hline \multicolumn{8}{|l|}{$3.0 \mathrm{~cd} / \mathrm{m}^{2}$} \\
\hline $1.5 \mathrm{cpd}$ & $-0.48^{* *}$ & $-0.55^{* *}$ & $-0.63^{* *}$ & $-0.54^{* *}$ & $-0.36^{*}$ & $-0.44^{* *}$ & 0.17 \\
\hline $3.0 \mathrm{cpd}$ & $-0.43^{* *}$ & $-0.43^{* *}$ & $-0.44^{* *}$ & $-0.47^{* *}$ & $-0.32^{*}$ & $-0.27^{*}$ & 0.23 \\
\hline $6.0 \mathrm{cpd}$ & $-0.25^{*}$ & $-0.29^{*}$ & $-0.36^{*}$ & $-0.36^{*}$ & $-0.27^{*}$ & $-0.27^{*}$ & 0.23 \\
\hline $12.0 \mathrm{cpd}$ & $-0.35^{*}$ & $-0.47^{* *}$ & $-0.34^{*}$ & $-0.52^{* *}$ & $-0.25^{*}$ & $-0.31^{*}$ & $0.41^{* *}$ \\
\hline $18.0 \mathrm{cpd}$ & -0.16 & $-0.29 *$ & -0.19 & -0.15 & 0.04 & -0.14 & 0.23 \\
\hline \multicolumn{8}{|l|}{$C S$ with glare $\left(3 \mathrm{~cd} / \mathrm{m}^{2}\right)$} \\
\hline $1.5 \mathrm{cpd}$ & $-0.45^{* *}$ & $-0.46^{* *}$ & $-0.45^{* *}$ & $-0.36^{*}$ & $-0.38^{*}$ & $-0.31^{*}$ & 0.23 \\
\hline $3.0 \mathrm{cpd}$ & $-0.30^{*}$ & $-0.29^{*}$ & $-0.36^{*}$ & $-0.28^{*}$ & -0.23 & -0.24 & $0.31^{*}$ \\
\hline $6.0 \mathrm{cpd}$ & $-0.50^{* *}$ & $-0.60^{* *}$ & $-0.52^{* *}$ & $-0.52^{* *}$ & $-0.35^{*}$ & $-0.41^{* *}$ & $0.46^{* *}$ \\
\hline $12.0 \mathrm{cpd}$ & 0.03 & 0.04 & -0.07 & -0.18 & -0.13 & -0.02 & 0.19 \\
\hline NEI-VFQ-25 & -0.16 & -0.20 & $-0.27^{*}$ & $-0.33^{*}$ & $-0.27^{*}$ & $-0.28^{*}$ & 1.00 \\
\hline
\end{tabular}

Abbreviations: cpd, cycles per degree; CS, contrast sensitivity; logMAR, logarithm of the minimum angle of resolution; NEL-VFQ-25, 25-item National Eye Institute Visual Functioning Questionnaire; RLVT, real-life vision test; Task 1, reading and Chinese character-picking task; Task 2, reading and Chinese character-picking task in the reduced illumination; Task 3, Fruit and vegetable picking; Task 4, buttons matching; Task 5, street sign/billboard recognition; Task 6, face recognition; VA, visual acuity.

All the correlative results of the $18.0 \mathrm{cpd}$ (contrast sensitivity with glare $\left(3 \mathrm{~cd} / \mathrm{m}^{2}\right)$ ) were 0 , so they were not included in the Spearman's correlation. ${ }^{*} P<0.05$ and ${ }^{* *} P<0.001$

\section{Relationship between clinical measures and NEI-VFQ-25}

Multiple regression analysis showed that the worse eye near visual acuity, worse eye distance visual acuity, and stereopsis are significant clinical predictors of the total NEI-VFQ-25 scores.

\section{Discussion}

In the current study, we have found that visual impairment, even relatively mild ones, is associated with decreased functional vision, both performance-based and self-assessed.

Our data revealed significant associations between RLVT and variety of clinical measures of visual function, independent of age, sex, educational background, RT, and the depressive and cognitive status. However, RLVT is not a surrogate measure of the clinical measures. It provides different information about a patient's level of actual visual ability from the standard clinical measures.

With view to previous publications, it was found that the self-assessed reports had relatively low correlations 
Table 4 Partial correlation analysis of RLVT, clinical measures, and the NEI-VFQ-25-after adjusting for age, years of education, MMSE, SDS, and the RT

\begin{tabular}{|c|c|c|c|c|c|c|c|}
\hline Variables & Task 1 & Task 2 & Task 3 & Task 4 & Task 5 & Task 6 & NEI-VFQ-25 \\
\hline \multicolumn{8}{|l|}{$V A(\log M A R)$} \\
\hline \multicolumn{8}{|l|}{ Distance } \\
\hline Binocular & $0.44^{* *}$ & $0.46^{* *}$ & $0.60^{* *}$ & $0.59^{* *}$ & $0.54^{* *}$ & $0.58^{* *}$ & -0.22 \\
\hline Better eye & $0.47^{* *}$ & $0.46^{* *}$ & $0.64^{* *}$ & $0.61^{* *}$ & $0.57^{* *}$ & $0.57^{* *}$ & -0.18 \\
\hline Worse eye & 0.18 & 0.23 & 0.14 & 0.18 & $0.29^{*}$ & $0.27^{*}$ & $-0.42^{* *}$ \\
\hline \multicolumn{8}{|l|}{ Near } \\
\hline Binocular & $0.72^{* *}$ & $0.64^{* *}$ & $0.62^{* *}$ & $0.74^{\star *}$ & $0.54^{* *}$ & $0.53^{* *}$ & -0.11 \\
\hline Better eye & $0.68^{* *}$ & $0.59^{* *}$ & $0.67^{* *}$ & $0.74^{* *}$ & $0.54^{* *}$ & $0.55^{* *}$ & -0.12 \\
\hline Worse eye & 0.22 & 0.22 & 0.18 & $0.33^{*}$ & 0.16 & 0.21 & $-0.40^{*}$ \\
\hline \multicolumn{8}{|l|}{ Intermediate } \\
\hline Binocular & $0.59^{* *}$ & $0.60^{* *}$ & $0.65^{\star *}$ & $0.58^{* *}$ & $0.52^{* *}$ & $0.58^{* *}$ & 0.01 \\
\hline Better eye & $0.54^{* *}$ & $0.58^{* *}$ & $0.57^{* *}$ & $0.53^{* *}$ & $0.40^{*}$ & $0.62^{* *}$ & 0.03 \\
\hline Worse eye & 0.24 & 0.23 & $0.29^{*}$ & $0.29^{*}$ & 0.22 & $0.32^{*}$ & $-0.31^{*}$ \\
\hline Stereopsis & $0.27^{*}$ & 0.22 & 0.08 & $0.31^{*}$ & 0.16 & 0.14 & $-0.49^{* *}$ \\
\hline Color vision & $0.42^{* *}$ & 0.20 & $0.26^{*}$ & $0.28^{*}$ & 0.12 & 0.20 & 0.09 \\
\hline \multicolumn{8}{|l|}{ CS (log units) } \\
\hline \multicolumn{8}{|l|}{$85 \mathrm{~cd} / \mathrm{m}^{2}$} \\
\hline $1.5 \mathrm{cpd}$ & $-0.58^{* *}$ & $-0.55^{* *}$ & $-0.69 * *$ & $-0.58^{* *}$ & $-0.45^{* *}$ & $-0.51^{* *}$ & 0.01 \\
\hline $3.0 \mathrm{cpd}$ & $-0.54^{* *}$ & $-0.54^{* *}$ & $-0.60^{* *}$ & $-0.68^{* *}$ & $-0.48^{* *}$ & $-0.45^{* *}$ & 0.12 \\
\hline $6.0 \mathrm{cpd}$ & $-0.47^{* *}$ & $-0.41^{*}$ & $-0.38^{*}$ & $-0.60 * *$ & $-0.29^{*}$ & $-0.36^{*}$ & 0.25 \\
\hline $12.0 \mathrm{cpd}$ & $-0.26^{*}$ & -0.19 & -0.17 & $-0.32^{*}$ & -0.06 & -0.24 & 0.21 \\
\hline $18.0 \mathrm{cpd}$ & -0.23 & -0.15 & -0.25 & -0.21 & -0.05 & -0.14 & 0.21 \\
\hline \multicolumn{8}{|l|}{$3 \mathrm{~cd} / \mathrm{m}^{2}$} \\
\hline $1.5 \mathrm{cpd}$ & $-0.51^{* *}$ & $-0.51^{* *}$ & $-0.59^{* *}$ & $-0.49^{* *}$ & $-0.36^{*}$ & $-0.38^{*}$ & 0.02 \\
\hline $3.0 \mathrm{cpd}$ & $-0.48^{* *}$ & $-0.46^{* *}$ & $-0.54^{* *}$ & $-0.53^{* *}$ & $-0.36^{*}$ & $-0.30^{*}$ & 0.19 \\
\hline $6.0 \mathrm{cpd}$ & $-0.29^{*}$ & $-0.31^{*}$ & $-0.43^{* *}$ & $-0.44^{* *}$ & $-0.29^{*}$ & -0.25 & 0.15 \\
\hline $12.0 \mathrm{cpd}$ & $-0.36^{*}$ & $-0.43^{* *}$ & $-0.28^{*}$ & $-0.50^{* *}$ & -0.22 & -0.24 & $0.31^{*}$ \\
\hline $18.0 \mathrm{cpd}$ & -0.20 & $-0.30^{*}$ & -0.21 & -0.17 & 0.03 & -0.11 & 0.25 \\
\hline \multicolumn{8}{|c|}{$C S$ with glare $\left(3 \mathrm{~cd} / \mathrm{m}^{2}\right)$} \\
\hline $1.5 \mathrm{cpd}$ & $-0.51^{* *}$ & $-0.51^{* *}$ & $-0.52^{* *}$ & $-0.43^{* *}$ & $-0.40^{*}$ & $-0.26^{*}$ & 0.16 \\
\hline $3.0 \mathrm{cpd}$ & $-0.32^{*}$ & $-0.26^{*}$ & $-0.39^{*}$ & $-0.27^{*}$ & -0.22 & -0.23 & 0.23 \\
\hline $6.0 \mathrm{cpd}$ & $-0.51^{* *}$ & $-0.57^{* *}$ & $-0.46^{* *}$ & $-0.48^{* *}$ & $-0.29^{*}$ & $-0.31^{*}$ & $0.29^{*}$ \\
\hline $12.0 \mathrm{cpd}$ & 0.09 & 0.10 & -0.03 & -0.14 & -0.24 & 0.02 & 0.11 \\
\hline NEI-VFQ-25 & -0.05 & -0.06 & -0.08 & -0.20 & -0.16 & -0.17 & 1.00 \\
\hline
\end{tabular}

Abbreviations: cpd, cycles per degree; CS, contrast sensitivity; logMAR, logarithm of the minimum angle of resolution; NEI-VFQ-25, t25-item National Eye Institute Visual Functioning Questionnaire; RLVT, real-life vision test; Task 1, reading and Chinese character-picking task; Task 2, reading and Chinese character-picking task in the reduced illumination; Task 3, Fruit and vegetable picking; Task 4, buttons matching; Task 5, street sign/billboard recognition; Task 6, face recognition; VA = visual acuity.

All the correlative results of the $18.0 \mathrm{cpd}$ (contrast sensitivity with glare $\left.\left(3 \mathrm{~cd} / \mathrm{m}^{2}\right)\right)$ were 0 , so they were not included in the Partial correlation. ${ }^{*} P<0.05$ and ${ }^{* *} P<0.001$.

with the PBMs. ${ }^{36,37}$ Similarly, our results provided a weak correlation between them. Particularly, after adjusting for the confounding factors, none of these statistical associations existed (Table 4). The RLVT was less influenced by the depressive conditions than the NEI-VFQ-25. It also demonstrated a stronger relationship with the traditional clinical measures than the NEI-VFQ25. These findings are consistent with the notion that PBMs are more closely related to clinical assessment and less susceptible to the confounding factors. ${ }^{36}$ In a word, the RLVT is considered to be the implementation of the measures of visual health, but it cannot replace the clinical measures or self-report questionnaires. All the three tools are unique in dealing with different aspect of evaluation for visual function. The NEI-VFQ-25 acts as a valid measure of how people feel about their ability to function, whereas the RLVT provides an instrument to measure how well individuals are able to perform daily activities. The best type of evaluation should incorporate both subjective and objective tests. 


\section{The validity of the RLVT}

Our initial goal was to validate the performance tasks data by using the clinical functional assessment results. Because the development of RLVT was based on the result of patients-centered questionnaires, it has content validity. Additionally, there was a statistically significant difference in the result of RLVT among subjects with different levels of visual condition. Finally, most of the subscales of RLVT were significantly correlated with the clinical measures of visual functions. All these strong relationships provide evidence of construct validity.

\section{Limitations}

First, the small number of subjects was the main limitation in our study. It is possible that additional relationships were not detected. Also, the subjects are from the same hospital and it may not be possible to validly generalize our findings to all individuals. More patients from different hospitals should be recruited in future study. Second, the time-instructed scoring scale still cannot fully represent the spectrum of visual damage. Especially, in the face and street signs recognition tasks, a few patients were confused about the rules and could not follow the testing procedure. This made RLVT easier to be influenced by the confounding factors other than visual ability. Another limitation is that we only compared the total score of the NEI-25 with the RLVT and clinical measure, but not the subscale scores. Therefore, it is possible that additional relationships were not detected. Moreover, measuring RT in our method would also depend on the patients' visual function, so the result may be influenced by this confounding factor. Additionally, the exclusion criteria removed all individuals with musculoskeletal or neurological disorders that might have influenced their testing results, and this may limit the applicability of our results to all patient subpopulations. Finally, the reliability of the RLVT was not assessed in this study population. Further testing to establish both test-retest and inter-rater reliability will need to be conducted before taking RLVT into consideration to use in a clinical setting.

\section{Strengths}

Although the use of different PBMs in different countries may make the comparison more difficult, our experience indicates that it is necessary to make them locally appropriate. In our study, we emphasized on the Chinese patients' preference and value. Tasks item selection has generally been based on subject's expressed priorities. All the tasks selected/designed in this study were based on prior research.
We mainly focused on the duration to complete a task, rather than an emphasis on accuracy alone. Our findings confirm that a measure based on time may better reflect the extent of the impairments than a pass/fail competency measure and may be worth pursuing as outcome measures when evaluating clinical interventions. ${ }^{19}$ Slow speed in performing a task is a big problem in everyday life for our participants. In particular, the patients, with mild to moderate vision impairment, are able to successfully perform the tasks, but may require a longer time than the normal-sighted ones.

In some prior studies, the efforts to design face/ street signs recognition tasks were mainly focused on the pass/fail competency scoring system. However, this scoring system may lead to problems, in such cases like a person who takes 4 min to correctly recognize a face would get the same score as the person who takes only $4 \mathrm{~s}$. In this way, the time-instructed scale may provide a more sensitive tool for further evaluation of different levels of visual impairment.

\section{The potential advantages of the PBMs}

PBMs can be easily administered and observed by doctors and may directly assess one's changes in actual performance. Therefore, they facilitate a more thorough evaluation of changes in functional outcomes and the efficacy of an intervention. They simultaneously provide an evaluation that works far better for patients in terms of demonstrating the real ability to perform daily tasks. Particularly in China, many elderly patients can hardly understand the meaning of visual acuity or contrast sensitivity. Therefore, it is difficult for them to know about their visual conditions. PBMs are useful in telling them which aspect of daily life was affected, how well they can perform according to their visual impairment, and also how much they can improve after the treatment. Also, the data provided by PBMs are clearly interpretable for both patients and clinicians, especially in the context of weighing the relative benefits of various treatments. Indeed, although the improvement of three lines on a visual acuity chart may seem impressive to doctors, the ability to inform a patient that they can expect to recognize the street signs easily after the clinical treatment is more encouraging.

\section{Recommendations for future instrument development}

Much remains to be done to make such measures as RLVT practical and valid instruments that can assess the functional vision over a wide range of degrees of visual damage. Next-generation instruments would benefit from using a more patient-focused, theory-driven 


\section{Conflict of interest}

The authors declare no conflict of interest. populations that they are evaluating. First, there is still little scientific understanding about the complex relationships between the standard clinical measures, self-report assessments and the visual-related ability to perform daily tasks. 8,21,23-26,36,37 Future development of RVLT should allow for more meaningful understanding in these relationships, so as to know how the various instruments complement one another, and finally, how well they can work together. Furthermore, a major need for future development is to determine the degree to which PBMs are sensitive to change in visual functioning over time. If functional abilities are to be considered as part of the evaluation of treatment effectiveness, then it is important to notion that the PBMs measures are sensitive to meaningful changes in visual functioning. If this information is incorporated, such instruments may be more strongly related to visual treatment decisions and clinically relevant treatment changes.

In conclusion, the results in our study highlight the potential usefulness of RLVT for assessing the visual status of cataract-affected individuals. RLVT appears to be a valid measure of visual ability that may provide information not obtainable from the standard clinical measures or subjective surveys.

\section{Summary}

What was known before

- Many visually impaired people have varied difficulties in day to day activities.

- Currently, the most-accepted assessments of visual function are the clinical tests, such as visual acuity and visual field.

- Vision-related questionnaires and surveys provided key information about the impact of visual damage from the patients' perspective.

- Both clinical tests and self-report questionnaires have inherent limitations, they may be inadequate in explaining impairments of everyday performance.

- Pioneering work in the development of vision-specific PBMs has demonstrated that this kind of assessment can be a reliable and valid method in assessing visual ability.

What this study adds

- In our study, a new type of vision-specific PBM was developed, the real-life vision test (RLVT).

- This study tries to analyze the relationship among RLVT, clinical measures, and self-report assessment of visual function, and the complex interactions among visual impairment, psychosocial status, as well as demographic factors.

- For the development of RLVT, a special questionnaire was designed for this purpose, including a broad range of vision-requiring tasks that represent many domains of daily life, which made the tasks more accordant to Chinese culture. 2011CB510200).

\section{Acknowledgements}

This work is supported by the grants from the National Basic Research Program of China (973 Program, No.

\section{References}

1 Dhital A, Pey T, Stanford MR. Visual loss and falls: a review. Eye (Lond) 2010; 24(9): 1437-1446.

2 Owsley C, McGwin G Jr. Depression and the 25-item National Eye Institute Visual Function Questionnaire in older adults. Ophthalmology 2004; 111(12): 2259-2264.

3 James H, Jenkinson E, Harrad R, Ezra DG, Newman S. Appearance concerns in ophthalmic patients. Eye (Lond) 2011; 25(8): 1039-1044.

4 Rubin GS, Munoz B, Bandeen-Roche K, West SK. Monocular vs binocular visual acuity as measures of vision impairment and predictors of visual disability. Invest Ophthalmol Vis Sci 2000; 41(11): 3327-3334.

5 Frost A, Eachus J, Sparrow J, Peters TJ, Hopper C, DaveySmith G et al. Vision-related quality of life impairment in an elderly UK population: associations with age, sex, social class and material deprivation. Eye (Lond) 2001; 15(Pt 6): 739-744.

6 Owsley C, McGwin G Jr., Scilley K, Meek GC, Seker D, Dyer A. Impact of cataract surgery on health-related quality of life in nursing home residents. Br J Ophthalmol 2007; 91(10): 1359-1363.

7 Williams GP, Pathak-Ray V, Austin MW, Lloyd AP, Millington IM, Bennett A. Quality of life and visual rehabilitation: an observational study of low vision in three general practices in West Glamorgan. Eye (Lond) 2007; 21(4): 522-527.

8 Chandrasekaran S, Wang JJ, Rochtchina E, Mitchell P. Change in health-related quality of life after cataract surgery in a population-based sample. Eye (Lond) 2008; 22(4): 479-484.

9 Tong L, Waduthantri S, Wong TY, Saw SM, Wang JJ, Rosman $\mathrm{M}$ et al. Impact of symptomatic dry eye on vision-related daily activities: the Singapore Malay Eye Study. Eye (Lond) 2010; 24(9): 1486-1491.

10 Worrall L, Hickson L, Barnett H, Lovie-Kitchin JE. The performance of older people on everyday visual tasks. Clin Exp Optom 1993; 76(4): 127-135.

11 Mangione CM, Lee PP, Pitts J, Gutierrez P, Berry S, Hays RD. Psychometric properties of the National Eye Institute Visual Function Questionnaire (NEI-VFQ). NEI-VFQ Field Test Investigators. Arch Ophthalmol 1998; 116(11): 1496-1504.

12 Mangione CM, Lee PP, Gutierrez PR, Spritzer K, Berry S, Hays RD. Development of the 25-item National Eye Institute Visual Function Questionnaire. Arch Ophthalmol 2001; 119(7): 1050-1058.

13 West SK, Rubin GS, Broman AT, Munoz B, Bandeen-Roche $\mathrm{K}$, Turano K. How does visual impairment affect performance on tasks of everyday life? The SEE Project. Salisbury Eye Evaluation. Arch Ophthalmol 2002; 120(6): 774-780. 
14 Clemons TE, Chew EY, Bressler SB, McBee W. National Eye Institute Visual Function Questionnaire in the Age-Related Eye Disease Study (AREDS): AREDS Report No. 10. Arch Ophthalmol 2003; 121(2): 211-217.

15 Unver YB, Yavuz GA, Sinclair SH. Interactive, computerbased, self-reported, visual function questionnaire: the PalmPilot-VFQ. Eye (Lond) 2009; 23(7): 1572-1581.

16 Lundstrom M, Pesudovs K. Questionnaires for measuring cataract surgery outcomes. J Cataract Refract Surg 2011;37(5): 945-959.

17 Duberstein PR, Sorensen S, Lyness JM, King DA, Conwell Y, Seidlitz L et al. Personality is associated with perceived health and functional status in older primary care patients. Psychol Aging 2003; 18(1): 25-37.

18 West SK, Rubin GS, Munoz B, Abraham D, Fried LP. Assessing functional status: correlation between performance on tasks conducted in a clinic setting and performance on the same task conducted at home. The Salisbury Eye Evaluation Project Team. J Gerontol A Biol Sci Med Sci 1997; 52(4): M209-M217.

19 Owsley C, McGwin G Jr, Sloane ME, Stalvey BT, Wells J. Timed instrumental activities of daily living tasks: relationship to visual function in older adults. Optom $\mathrm{Vis} \mathrm{Sci}$ 2001; 78(5): 350-359.

20 Szlyk JP, Seiple W, Fishman GA, Alexander KR, Grover S, Mahler CL. Perceived and actual performance of daily tasks: relationship to visual function tests in individuals with retinitis pigmentosa. Ophthalmology 2001; 108(1): 65-75.

21 Haymes SA, Johnston AW, Heyes AD. Relationship between vision impairment and ability to perform activities of daily living. Ophthalmic Physiol Opt 2002; 22(2): 79-91.

22 Owsley C, Sloane M, McGwin G Jr, Ball K. Timed instrumental activities of daily living tasks: relationship to cognitive function and everyday performance assessments in older adults. Gerontology 2002; 48(4): 254-265.

23 Altangerel U, Spaeth GL, Steinmann WC. Assessment of function related to vision (AFREV). Ophthalmic Epidemiol 2006; 13(1): 67-80.

24 Warrian KJ, Lorenzana LL, Lankaranian D, Dugar J, Wizov SS, Spaeth GL. Assessing age-related macular degeneration with the ADREV performance-based measure. Retina 2009; 29(1): 80-90.

25 Richman J, Lorenzana LL, Lankaranian D, Dugar J, Mayer JR, Wizov SS et al. Relationships in glaucoma patients between standard vision tests, quality of life, and ability to perform daily activities. Ophthalmic Epidemiol 2010; 17(3): 144-151.

26 Warrian KJ, Lorenzana LL, Lankaranian D, Dugar J, Wizov SS, Spaeth GL. The assessment of disability related to vision performance-based measure in diabetic retinopathy. Am J Ophthalmol 2010; 149(5): 852-860; e1.

27 Charalampidou S, Nolan J, Loughman J, Stack J, Higgins G, Cassidy L et al. Psychophysical impact and optical and morphological characteristics of symptomatic nonadvanced cataract. Eye (Lond) 2011; 25(9): 1147-1154.

28 Folstein MF, Folstein SE, McHugh PR. 'Mini-mental state'. A practical method for grading the cognitive state of patients for the clinician. J Psychiatr Res 1975; 12(3): 189-198.

29 Zung WW, Richards CB, Short MJ. Self-rating depression scale in an outpatient clinic. Further validation of the SDS. Arch Gen Psychiatry 1965; 13(6): 508-515.

30 Chylack LT Jr., Wolfe JK, Singer DM, Leske MC, Bullimore MA, Bailey IL et al. The Lens Opacities Classification System III. The Longitudinal Study of Cataract Study Group. Arch Ophthalmol 1993; 111(6): 831-836.

31 Bailey IL, Lovie JE. New design principles for visual acuity letter charts. Am J Optom Physiol Opt 1976; 53(11): 740-745.

32 Colenbrander A, Fletcher D. Evaluation of a new Mixed Contrast Reading Card. Invest Ophthalmol Vis Sci 2004; 45.

33 Hong YT, Kim SW, Kim EK, Kim TI. Contrast sensitivity measurement with 2 contrast sensitivity tests in normal eyes and eyes with cataract. J Cataract Refract Surg 2010; 36(4): 547-552.

34 Ao M, Chen X, Huang C, Li X, Hou Z, Zhang C et al. Color discrimination by patients with different types of lightfiltering intraocular lenses. J Cataract Refract Surg 2010; 36(3): 389-395.

35 West SK, Munoz B, Rubin GS, Bandeen-Roche K, Broman AT, Turano KA. Compensatory strategy use identifies risk of incident disability for the visually impaired. Arch Ophthalmol 2005; 123(9): 1242-1247.

36 Friedman SM, Munoz B, Rubin GS, West SK, BandeenRoche K, Fried LP. Characteristics of discrepancies between self-reported visual function and measured reading speed. Salisbury Eye Evaluation Project Team. Invest Ophthalmol Vis Sci 1999; 40(5): 858-864.

37 Klein BE, Klein R, Lee KE, Cruickshanks KJ. Associations of performance-based and self-reported measures of visual function. The Beaver Dam Eye Study. Ophthalmic Epidemiol 1999; 6(1): 49-60. 